\title{
Prevalence, Severity and Consequences of Dental Caries among Children: A study in a Private Dental College and Hospital, Dhaka, Bangladesh
} Nurul $\mathrm{F}^{*}$, Rahman $\mathrm{M}^{2}$, Saha $\mathrm{S}^{3}$

${ }^{1}$ Dr. Farhana Nurul, Assistant Professor, Dental Unit, MARKS Medical College \& Hospital, Dhaka, Bangladesh

${ }^{2}$ Dr. Mukhlechur Rahman, Assistant Professor, Department of Oral Anatomy, Community Based Medical College Bangladesh, Mymensingh, Bangladesh

${ }^{3}$ Dr. Sanjoy Saha, Lecture, Department of Prosthodontics, Ibrahim Medical College, Dhaka, Bangladesh

| Received: 30.12 .2020 | Accepted: 13.01.2021 | Published: 28.03.2021

*Corresponding author: Dr. Farhana Nurul

Abstract Original Research Article

Objectives: Dental caries still persist among majority of the World's population with high prevalence of untreated cases seen among vulnerable groups. The study seeks to assess dental caries prevalence, severity and consequences among institutionalized orphans in Dhaka, Bangladesh. Methods: A cross-sectional descriptive study conducted in the Dental Unit of MARKS Medical College \& Hospital during the period from January 2017 to June 2019. Multi-stage sampling technique was used to screened participants for dental caries using dmft/DMFT, and PUFA/pufa indices, and International Caries Detection Assessment System (ICDAS) codes. Results: The study had 152 children; 102 (67.1\%) males, 50 (32.9\%) females (M/F 2.04:1), age range of 4-17 years and mean age of $11.36 \pm 3.62$ years. Dental caries prevalence was $34(22.4 \%)$ with mean $\mathrm{dmft} / \mathrm{DMFT}$ score of $0.21 \pm 0.41 / 0.14 \pm 0.35(\mathrm{M} / \mathrm{F}$ ratios $0.19 \pm 0.59 / 0.18 \pm$ 0.45: $0.21 \pm 0.66 / 0.80 \pm 0.27)$. The ICDAS code $6(44.4 \%)$ was prominent followed by code $2(22.2 \%)$. PUFA/pufa prevalence was $18.4 \%$ with mean score of $0.30 \pm 0.46 / 0.22 \pm 0.50$ and $\mathrm{P} / \mathrm{p}(42.6 \%)$ component had highest value. The untreated caries PUFA/pufa ratio was $51.9 \%$ while the decayed tooth without pulp involvement was $48.1 \%$. Conclusion: Dental caries was more prevalent in deciduous dentition and female subjects; with advanced lesion higher than the early carious lesion.

Keywords: Dental caries, Dentition, Children.

Copyright $(\mathcal{C} 2021$ The Author(s): This is an open-access article distributed under the terms of the Creative Commons Attribution 4.0 International License (CC BY-NC 4.0) which permits unrestricted use, distribution, and reproduction in any medium for non-commercial use provided the original author and source are credited.

\section{INTRODUCTION}

Dental caries affects the bulk of the world's population and has been implicated in child's restricted activities at college and residential thus causing lost school hours, a distraction from learning and play, and it's the foremost important reason behind tooth loss in children and young people [1-3]. Prevalence of caries varies significantly between countries among different socio-economic status, cultures, ethnicities, gender, age groups, and can cause a severe amount of pain, suffering, and burden if left untreated $[2,3,5,6]$. It can be particularly so among the vulnerable and socially marginalized children in both developing and developed countries [7, 8]. There are about four hundred million children worldwide [9] and an estimated 17.5 million classified as Vulnerable Children (O.V.C) in Nigeria with HIV/AIDS accounting for the bulk of cases [10, 11]. A baby aged zero to 17-years who has lost one or both parents [12]. Parenthood could be a known reinforcing factor that exerts a strong influence on a child's healthy development and healthy oral hygiene practices [13]. In orphanages, the complete unfolding of potentials may be hampered by certain social elements like parental inadequacy with an occasional caregiver to child ratio [11], environmental deprivation, inadequate oral healthcare materials, poor nutrition, and emotional disturbances have led to increased risk of preventable diseases including dental caries [14-20]. The implications of tooth decay on the community are considerable and treatment is commonly provided as an emergency [16, 17, 21-23].The study seeks to assess tooth decay prevalence, severity, and consequences in children in Dhaka city.

\section{METHODS AND MATERIALS}

This cross-sectional descriptive study conducted on children aged 2-17-years visited in the Dental Unit of MARKS Medical College \& Hospital, Dhaka, Bangladesh during the period from January 2017 to June 2019. However, those who declined to participate and/or critically ill were excluded. Multi- 
stage sampling method was used; stratified random sampling with proportionate allocation, systematic random sampling technique for subject selection and simple random sampling by balloting to choose a starting point. The WHO 2013 Oral Health Assessment Form for Children was adapted to include sociodemography and indices such as dmft/DMFT, ICDAS and PUFA/pufa [24-28]. Participants screened for dental caries were seated on a chair with full illumination of intra-oral structures under natural daylight. The diagnostic criteria for dental caries correspond to ICDAS code 2 . The d/D component of $\mathrm{dmft} / \mathrm{DMFT}$ was used to determine dental caries prevalence, ICDAS for caries severity and PUFA/pufa for consequences of untreated dental caries. The interview-administered questionnaires were filled by paired dental therapists as dentists communicate intraoral findings to them. Interexaminer variability was done using 20 children at the Child Dental Department clinic with kappa statistics set at 0.75. Statistical analysis was done using SPSS version 17.0 (SPSS Inc. Chicago, IL, USA). A confidence interval of $95 \%$ was used in this study and a $\mathrm{p}$-value $\leq 0.05$ was considered statistically significant. Ethical approval was received from Aminu Kano Teaching Hospital Research and Ethics Committee, and permissions from Kano State Ministry of Women Affairs and Social Development and orphanage authorities.

\section{RESULTS}

The study had 152 children; 102 (67.1\%) male and $50(32.9 \%)$ female participants with age range of 417 years and mean age of $11.36 \pm 3.62$ years. The mean ages for male /female subjects were $11.83 \pm 3.74 / 10.38 \pm 3.19$ years respectively. The prominent age category was 14-17 years and majority $(66.4 \%)$ of the subjects were at their primary level of education. Dental caries prevalence was 34 (22.4\%) with mean $\mathrm{dmft} / \mathrm{DMFT}$ score of $0.21 \pm 0.41 / 0.14 \pm$ 0.35 . The male/female mean $\mathrm{dmft} / \mathrm{DMFT}$ scores ratios are $0.19 \pm 0.59 / 0.18 \pm 0.45$ and $0.21 \pm 0.66 / 0.80 \pm 0.27$ respectively. Dental caries increased with increasing age with statistical significant difference observed. The d/D component was the main contributor to $\mathrm{dmft} / \mathrm{DMFT}$ with the second deciduous (35.2\%) and first permanent molars $(33.3 \%)$ mostly affected. The most frequent ICDAS was code $6(44.4 \%)$ and followed by code $2(22.2 \%)$. The prevalence of PUFA/pufa among the subjects was $18.4 \%$ with PUFA/pufa mean score of $0.30 \pm 0.46 / 0.22 \pm 0.50$. Teeth with pulp involvement $(\mathrm{P} / \mathrm{p})$ teeth had the highest mean value of $0.24 / 0.19$, followed by abscessed (A/a) teeth with mean score of $0.06 / 0.04$ while no ulceration and fistula were observed. The untreated caries PUFA/pufa ratio was $51.9 \%$ while the decayed teeth without pupal involvement were $48.1 \%$ teeth.

Table-1: The mean $\mathrm{dmft} / \mathrm{DMFT}$ against gender and age category

\begin{tabular}{|l|l|l|l|}
\hline \multicolumn{2}{|l|}{ No of subjects } & Mean dmft \pm SD $\Sigma(\mathbf{d m f t})$ & Mean DMFT \pm SD $\Sigma($ DMFT) \\
\hline Gender & 102 & $0.19 \pm 0.59$ & $0.18 \pm 0.45$ \\
\hline Male & 50 & $0.21 \pm 0.66$ & $0.80 \pm 0.27$ \\
\hline Female & 152 & $0.21 \pm 0.41$ & $0.14 \pm 0.35$ \\
\hline Total & 0.518 & 0.169 \\
\hline p-value & \multicolumn{5}{|l|}{} \\
\hline Age & $0.25 \pm 0.46$ & $0.00 \pm 0.00$ \\
\hline $2-5$ years & 8 & $0.49 \pm 0.93$ & $0.02 \pm 0.15$ \\
\hline $6-9$ years & 47 & $0.17 \pm 0.67$ & $0.22 \pm 0.47$ \\
\hline $10-13$ years & 41 & $0.00 \pm 0.00$ & $0.21 \pm 0.49$ \\
\hline $14-17$ years & 56 & $0.21 \pm 0.41$ & $0.14 \pm 0.35$ \\
\hline Total & 152 & $0.002 \mathrm{~S}$ & $0.036 \mathrm{~S}$ \\
\hline p-value & &
\end{tabular}

Level of significance $(\mathrm{p}$-value $)=0.05, \mathrm{~S}=$ statistically significant difference

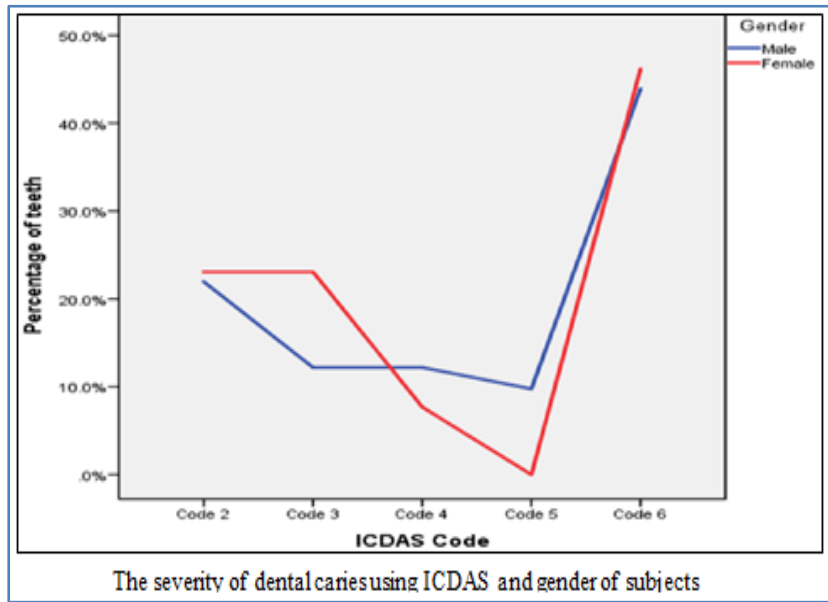

Fig-1: The severity of dental caries using ICDAS and gender of subjects 


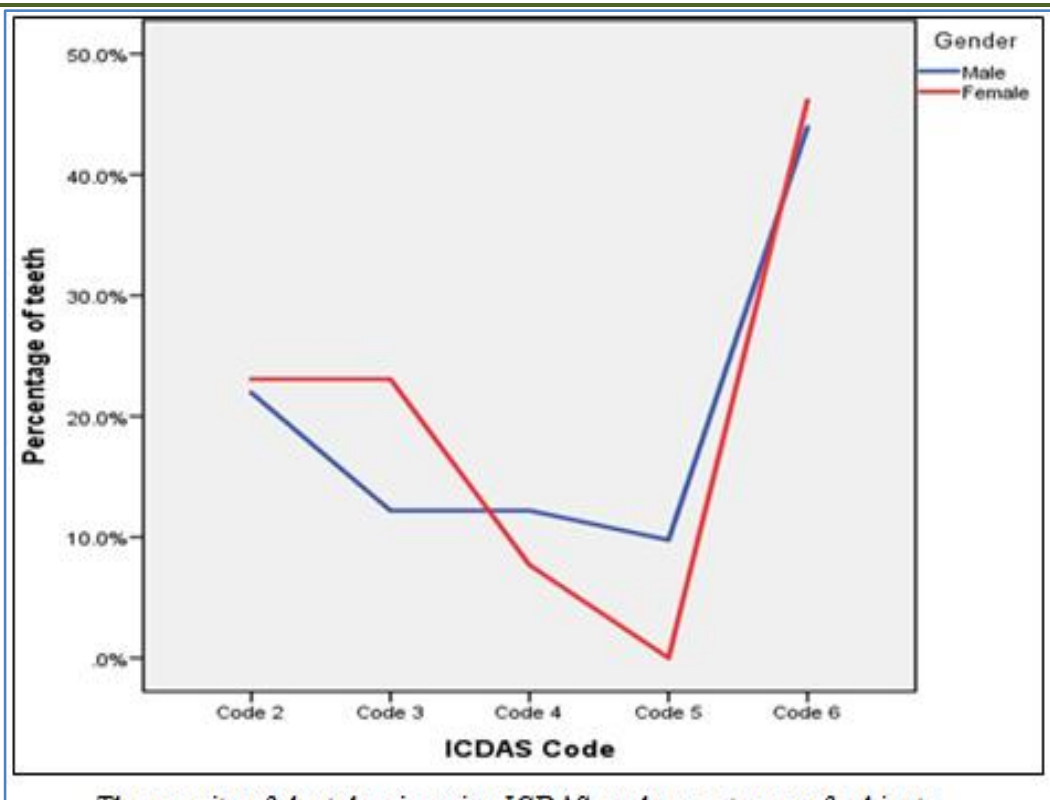

The severity of dental cariesusing ICDAS and age category of subjects

Fig-2: The severity of dental caries using ICDAS and age category of subjects

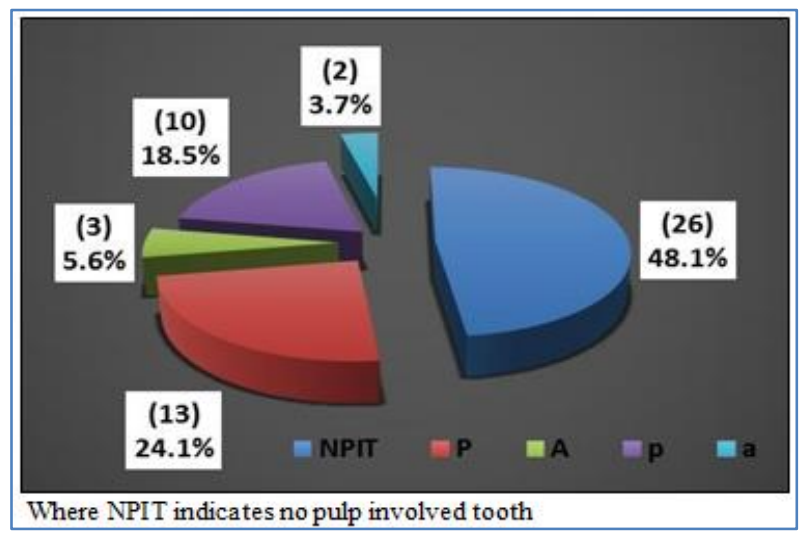

Fig-3: Percentage distribution of PUFA/pufa index and decayed teeth with no pulp involvement

\section{DISCUSSION}

Dental caries when left untreated, could lead to more serious dentofacial health problems such as toothache, dental abscess, facial space cellulitis, and septicemia [3]. These consequences have reflected among children as poor school attendance, eating problems, speaking, and learning problems [1, 4]. Anecdotal shreds of evidence opined that the socially marginalized, vulnerable,

and disadvantaged/underprivileged groups bear much of the health burdens in both developed and developing countries $[2,8]$. The study had more male participants which might not be unrelated to girls being given out early for marriage in the study environment. Ojahanon et al. [13], Arpita et al. [21], Rakesh et al. [22], and Abhishek et al. [23] had reported earlier a similar ratio whereas other researchers [10, 28, 29] observed more female than male subjects in a similar environment. Although the dominant age category was 14-17-years, however, the majority of the children were in their primary level of education. This finding does not reflect the educational status of children of similar age group children who live with their parents or those from the southern part of Nigeria [30]. Prevalence of dental caries $(22.4 \%)$ was found to be affected by demographic factors [31] with higher. DMFT scores in females when compared to their male counterparts. It was also found as increasing along the age gradient. This can be attributed to a higher inclination to consume sugary diets between girls that encourage bacterial growth which may lead to the development of dental caries [4, 31]. Morover, refined sugars are readily available and sold at cheap rates in the study area [31, 34]. Furthermore, increased intra-oral time predispose susceptible tooth to dental caries $[1,23,27,32,33]$. The study recorded low dental caries prevalence among the children which can be attributed to the non-cariogenic nature of orphanage children's diets as reported by other researchers [21, 28, 35, 36]. Although, higher prevalence rates were reported among school children of similar age categories in the urban and rural areas of Southern Nigeria [29]. The total mean dmft/DMFT was found to be lower than the WHO 1.5DMFT target set for children of similar age categories in orphanages [22, 27, 36, 37], and schools [31, 35]. The decayed component (DT) accounted for $98 \%$ of the DMFT score, indicative of poor utilization of restorative care and/or sign of oral preventive care negligence. Shanbog et al. [27] and Rehman et al. [32] reported similar findings and opined that subjects from socioeconomically disadvantaged backgrounds have high dental caries prevalence which they attributed to low dental care service utilization. The severity of untreated carious lesions found were in their advanced stage similar to those with low utilization of dental services [38, 39]. This was evident as $51.9 \%$ of the decayed teeth found had progressed to the pulp. The large contribution of decayed permanent to PUFA index 
Nurul F et al., Sch J Dent Sci, Mar, 2021; 8(3): 102-106

may lead to tooth fatality, hence an issue of dental public health concern among these vulnerable children. This shows a high index of unmet restorative care needs among these institutionalized children. Previous reports collected from developing countries discovered that most carious lesions often remain untreated and later on, present as dental emergencies in children's hospitals $[27,40]$. Care-giver negligence and poor supervision of the children's oral hygiene practices may be responsible for this trend. Parents are known to be the primary motivating factor to their wards as they closely monitor, mentor, and supervise their children's oral hygiene practices. Such children tend to have high met restorative care needs than children from the orphanages [13, 22, 23, 27, 36].

\section{CONCLUSIONS AND \\ RECOMMENDATIONS}

Although dental caries prevalence was low among the respondents, however, the high number of untreated decayed component showed high unmet restorative care needs in these children. We, therefore, recommend regular dental clinic visits for the children, regular Oral health promotion/outreaches by Oral health professionals to increase oral healthcare awareness, and intervention aimed towards prevention as contained in the WHO Basic Package of Oral Care (BPOC) for this vulnerable children. However, there is a need for further study on the Oral health knowledge, attitude, and practices of their caregivers.

\section{Study limitation}

The assessment of caries was based on the WHO criteria which do not require the use of radiographs. Early enamel caries could be missed especially in the interproximal areas.

\section{REFERENCES}

1. World Health Organization. Oral Health. Fact sheet. 2012, 318. Available at: www.who.Inhfrjjfre;bvt/media centre/factsheets/fs318/en/index.htm.

2. Sheiham A. Oral health, General Health and quality of life. Bull World Health Organ. 2005; 83(9):644.

3. American Dental Association: Healthy mouth, healthy body. JADA. 2006; 137:563.

4. Petersen PE, Bourgeois D, Hiroshi O. The Global burden of oral diseases and risk to oral health. Bull World Health Organ. 2005; 83:661-9.

5. Nishi MSJ, Carlson P, Bratthall D. Caries experience of some countries and areas expressed by the significant caries index. Community Dent Oral Epidemol. 2002; 30:296-301.

6. Wondowossen F, Astrom AN, Bjorvatn K, Barsen A. The relationship between dental caries and dental fluorosis in areas with moderate and high drinking water in Ethiopia. Community Dent Oral Epidemiol. 2004; 32:337-44.
7. Petersen PE. Improvement of oral health in African in the 21 st century-the role of the WHO global oral health program. Dev. Dent. 2004; 5:9-20.

8. Aline RFC, Fabio LM, Tais SB, Puppin-Rontani RM. Influence of family environment on children's oral health: a systematic review. J pediatr. (Rio J.). 2013; 89:2.

9. UNICEF Data on orphans by region to 2010 [chart]" in children and youth in History Item \#293, http://chnm. gwu.edu/cyh/primary-sources/293.

10. Oladokun RE, Brown BJ, Jacob NE, Osinusi K. HIV infection in orphanages in South Western Nigeria. Nigerian Journal of Paediatrics. 2011; 38(1):4-8.

11. UNICEF Press Center: Millions of Orphans in Nigeria need care and access to basic services; 2005.

12. The Permanent Committee for Academic Researches and issuing fatwas, Kingdom of Saudi Arabia. The duration of orphanhood fatwa, 2011. http://www.alifa. net

13. Ojahanon PI, Akionbare O, Umoh AO. The oral hygiene status of institution dwelling orphans in Benin City, Nigeria. Niger J Clin Pract. 2013; 16:41-4.

14. Amoaka JF, Padmadas SS, Smith PW. Orphanhood and Vulnerability: A conduit to poor child health outcome in Rwanda. Aids care. 2010; 22:314-23.

15. Sadeq AA, Walid AA, Esam SH. Oral lesions and dental status among institutionalized orphans in Yemen: a matched case-control study. Contemp Clin Dent. 2014; 5(1):81-84.

16. Mouko A, Mbika-Cardorelle A, Mboungou V, Mambou JB, Ibara JR, Senga P. Orphans in Brazzaville orphanages. Sante. 2009; 19(1):21-3.

17. Muralidharan D, Fareed N, Shanthi M. Comprehensive dental health care program at an orphanage in Nellore district of Andhra Pradesh, India. Indian J Dent Res. 2012; 23:171-5.

18. Siddiqui NJ. Adolescent Orphan girls in Delhi: A sociological profile; New Delhi; Regency Publications. 1997; 8:143.

19. Towanda N. Psychosocial support to Orphans and Vulnerable children, 2006. Available from: URL: http://www.wordmart.com

20. Petersen PE, Bourgeois D, Hiroshi O. The Global burden of oral diseases and risk to oral health. Bull World Health Organ. 2005; 83:661-9.

21. Arpita M, Neeta M, Deepak U, Shiva K, Deepak S, Uday M. Oral and dental health status in orphan children of Lucknow. Indian Journal of Community Health. 2014; 26:2.

22. Rakesh KG, Vinay K, Shivani K. Pinaka P, Barjinder S, Chitra A. Prevalence of dental caries, treatment needs and oral hygiene practices among orphanage children. Journal of peers. 2013; 1:1.

23. Abhishek S, Anupama G, Sonia P, Vasim R, Sudhanshu S, Antim BS. Oral Health Status and Treatment Needs among Orphanage Children of 
Nurul F et al., Sch J Dent Sci, Mar, 2021; 8(3): 102-106

Jaipur City, India. Sch. J App. Med. Sci. 2014; 2(5D):1776-1780.

24. World Health Organization, author. Oral health surveys- Basic Method. 5th edn. Geneva: WHO, 2013.

25. ICDAS Foundation: International Caries Detection Assessment System. ICDAS; 2014.

26. Ozeigbe EO, Esan TA. Prevalence and clinical consequences of untreated dental caries using PUFA index in suburban Nigerian school children. Eur Arch Paediatr Dent. 2013; 14:227-231.

27. Shanbog R, Godhi BS, Nandlal B, Kumar SS, Raju $\mathrm{V}$, Ramshmi S. Clinical consequences of untreated dental caries evaluated using PUFA Index in orphanage children from India. J Int Oral Health. 2012; 5(5):1-9.

28. Anna Akbari, Ulrika Bendz. Caries prevalence among primary school children in Old Mutare, Zimbabwe: An epidemiological study. Karolinska Institutet. 2010, 1810-1-30.

29. Greta M, Julija N. Effectiveness of a motivational and practical skills development methods on the oral hygiene of orphans' children in Kaunas, Lithuania. J. Oral and Maxillofacial Research; 2015.

30. Habibu Mohammed Umar, Russayani Ismail, Roslan Abdul-Hakim. Regional Inequality of Educational Attainment in Nigeria. British Journal of Economics, Management \& Trade. 2014; 4(3):420-430.

31. Folayan MO, Chukwumah NM, Onyejaka N, Adeniyi AA, Olatosi OO. Appraisal of the National response to the caries epidemic in children in Nigeria. BMC Oral Health. 2014; 101:25-29.

32. Rehman MM, Mahmood N, Rehman B. The relationship of caries with oral hygiene status and extraoral risk factors. J Ayub Med Coll Abbottabad. 2008; 20(1):103-8.

33. Camacho GA, Camacho E, Rodriguez RA, Guille A, Juarez HM, Perez GM. Predisposing factors for dental caries in girls at an orphanage of Mexico City. Acta Pediatr Mex. 2009; 30(2):71-6.

34. Sanu OO, Oredugba FA, Adebola RA. Oral and dental diseases among children and adolescents in Kano Nigeria. J Braz Res Pediatr Dent Int Clin. 2010, 445450.

35. Dixit S, Chaudhary M, Singh A. Molluscum contagiosum and dental caries: A pertinent combination. Journal of Indian Society of Pedodontics and Preventive Dentistry. 2009 Oct 1;27(4):197.

36. O'sullivan EA, Stephens AJ. The Oral and Dental Status of Children residing in a Romanian Orphanage. Int. J Paediatr Dent. 1997; 7:41-2.

37. Khedekar M, Suresh KV, Parkar MI, Malik N, Patil S, Taur S, Pradhan D. Implementation of oral health education to orphan children. Journal of the College of Physicians and Surgeons Pakistan. 2015 Dec 1;25(12):856-9.

38. Kalyana CP, Shashidar A, Sravan KY. Unmet restorative treatment needs among orphanage children of Uttara Kannada District. Journal of Education and Ethics in Dentistry. 2014; 14(2):6568.

39. Erica Simone dos Santos Souza1, Ana Cristina Barreto Bezerra, Rodrigo Ferreira Silva Guedes de Amorim, Tatiana Degani Paes Leme Azevedo. Caries Diagnosis in the Mixed Dentition Using ICDAS II. Brazilian Research in Pediatric Dentistry and Integrated Clinic. 2015; 15(1):13-21

40. Adeyemo DO. Local Government and Health Care Delivery in Nigeria: A Case Study. J Hum. Ecol. 2005; 18(2):149-160. 